\title{
Glyoxalase 1 copy number variation in patients with well differentiated gastro-entero-pancreatic neuroendocrine tumours (GEP-NET)
}

\author{
Mingzhan Xue ${ }^{1}$, Alaa Shafie ${ }^{1,2}$, Talha Qaiser ${ }^{3}$, Nasir M. Rajpoot $^{3}$, Gregory Kaltsas $^{4}$, \\ Sean James ${ }^{4}$, Kishore Gopalakrishnan ${ }^{4}$, Adrian Fisk ${ }^{4}$, Georgios K. Dimitriadis ${ }^{1,4,6}$, \\ Dimitris K. Grammatopoulos ${ }^{1,4}$, Naila Rabbani ${ }^{1,5}$, Paul J. Thornalley ${ }^{1,5, *}$ and Martin \\ O. Weickert ${ }^{1,4,6, *}$ \\ ${ }^{1}$ Division of Translational Medicine, Clinical Sciences Research Laboratories, Warwick Medical School, University of Warwick, \\ University Hospital, Coventry, U.K. \\ ${ }^{2}$ Faculty of Applied Medical Sciences, Taif University, Taif, Kingdom of Saudi Arabia \\ ${ }^{3}$ Department of Computer Sciences, University of Warwick, Coventry, U.K. \\ ${ }^{4}$ University Hospitals Coventry \& Warwickshire NHS Trust, The ARDEN NET Centre, ENETS CoE, Coventry, U.K. \\ ${ }^{5}$ Warwick Systems Biology Centre, Senate House, University of Warwick, Coventry, U.K. \\ ${ }^{6}$ Coventry University, Centre for Applied Biological \& Exercise Sciences, Coventry, U.K. \\ *Joint corresponding author \\ Correspondence to: Martin O. Weickert, email: martin.weickert@uhcw.nhs.uk
}

Keywords: Glyoxalase, multi-drug resistance, glycation, copy number variation, gastro-entero-pancreatic neuroendocrine tumour Received: October 11,2016 Accepted: June 27, $2017 \quad$ Published: August 16, 2017

Copyright: Xue et al. This is an open-access article distributed under the terms of the Creative Commons Attribution License 3.0 (CC BY 3.0), which permits unrestricted use, distribution, and reproduction in any medium, provided the original author and source are credited.

\section{ABSTRACT}

Background: The glyoxalase-1 gene (GLO1) is a hotspot for copy-number variation (CNV) in human genomes. Increased GLO1 copy-number is associated with multidrug resistance in tumour chemotherapy, but prevalence of GLO1 CNV in gastroentero-pancreatic neuroendocrine tumours (GEP-NET) is unknown.

Methods: GLO1 copy-number variation was measured in 39 patients with GEPNET (midgut NET, $n=25$; pancreatic NET, $n=14$ ) after curative or debulking surgical treatment. Primary tumour tissue, surrounding healthy tissue and, where applicable, additional metastatic tumour tissue were analysed, using real time qPCR. Progression and survival following surgical treatment were monitored over $4.2 \pm 0.5$ years.

Results: In the pooled GEP-NET cohort, GLO1 copy-number in healthy tissue was 2.0 in all samples but significantly increased in primary tumour tissue in $43 \%$ of patients with pancreatic NET and in $72 \%$ of patients with midgut NET, mainly driven by significantly higher GLO1 copy-number in midgut NET. In tissue from additional metastases resection (18 midgut NET and one pancreatic NET), GLO1 copy number was also increased, compared with healthy tissue; but was not significantly different compared with primary tumour tissue. During mean 3 - 5 years follow-up, 8 patients died and 16 patients showed radiological progression. In midgut NET, a high GLO1 copynumber was associated with earlier progression. In NETs with increased GLO1 copy number, there was increased Glo1 protein expression compared to non-malignant tissue.

Conclusions: GLO1 copy-number was increased in a large percentage of patients with GEP-NET and correlated positively with increased Glo1 protein in tumour tissue. Analysis of GLO1 copy-number variation particularly in patients with midgut NET could be a novel prognostic marker for tumour progression. 


\section{INTRODUCTION}

Glyoxalase 1 (Glo1) is part of the cytosolic glyoxalase system present in all human cells. Glo1 catalyses the glutathione-dependent metabolism of the reactive metabolite methylglyoxal (MG) - Figure 1A. MG is formed mainly by the low-level spontaneous degradation of triosephosphate intermediates of anaerobic glycolysis [1]. It is a potent glycating agent of protein and DNA, forming mainly the argininederived hydroimidazolone adduct of arginine residues, MG-H1, in proteins; and mainly a mixture of isomeric imidazopurinones, MGdG, of DNA - Figures $1 \mathrm{~B}$ and $1 \mathrm{C}$ $[2,3]$. MG-derived adducts of protein lead to protein inactivation and dysfunction and adducts of DNA are associated with DNA strand breaks and mutagenesis [4]. Glo1 suppresses the concentration of MG to low levels and thereby protein and DNA adducts are also suppressed to low, tolerable levels in protein and DNA - ca. $1-5 \%$ of protein and 1 in $10^{5}$ nucleotides in DNA $[3,5,6]$. In an animal model of hepatocellular carcinogenesis, GLO1 was found to be a tumour suppressor gene, suggesting that MGdG-linked mutations on some occasions lead to cell transformation and malignancy [7]. In established tumours increased Glo1 expression is a mediator of multidrug resistance (MDR) [8], indicating that MG-mediated cytotoxicity may contribute to the mechanism of action of antitumour agents - possibly by induction of apoptosis and anoikis (cell detachment stimulated apoptosis) [9-11]. Cell permeable inhibitors of Glo1 are potential anti-tumour agents and counter Glo1-overexpression mediated MDR [12] but none have yet been developed for clinical use reviewed in $[11,13]$.

The human GLO1 gene is located in chromosome 6 at locus $6 \mathrm{p} 21.2$ [14]. It consists of $12 \mathrm{~kb}$ with five introns separating six exons [15]. It is a hotspot for copy number variation $(\mathrm{CNV})$ in non-malignancy. In constructing a first-generation CNV map of the human genome, Redon et al. found a total of $1,447 \mathrm{CNV}$ regions covering $12 \%$ of the genome. GLO1 was the only gene found in a copied region of $c a .122 \mathrm{~kb}$ at $c a .2 \%$ prevalence [16]. GLO1 $\mathrm{CNV}$ was confirmed in a further human population study [17] and also found in other primates and mice [18-20]. GLO1 CNV is functional - increasing Glo1 expression by $3-4$ fold in all tissues and cells tested [18]. Importantly, GLO1 undergoes amplification in human tumours [21]. In a survey of 520 human tumours, increased GLO1 copynumber was found at a mean prevalence of $8 \%$. The highest prevalence was in breast cancer (19\%), small cell lung cancer (16\%) and non-small cell lung cancer $(11 \%)$ [21]. The prevalence of GLO1 copy-number increase in patients with gastro-entero-pancreatic neuroendocrine tumours (GEP-NET) has not been investigated to date.

GEP-NETs develop from neuroendocrine cells of the gastrointestinal tract (GI) mucosa and the pancreatic islet cells. The prevalence of GEP-NETs is thought to be 35 per 100,000 of the population [22], with pancreatic NETs (pNETs) representing approximately one third of cases. The mainstay of clinical treatment is surgical resection of the primary tumour and when possible of metastatic disease [23]. However, as a considerable number of patients with GEP-NETs present with metastatic disease not amenable to surgical resection, further medical treatment is required. Somatostatin analogues represent the first line of treatment for both functioning symptoms and systemic tumour control in patients with well differentiated GEP-NET $[24,25]$. Additional therapeutic options include peptide receptor radionuclide therapy and, mainly in patients with pancreatic NET, chemotherapy with alkylating agents such as Streptozotocin (STZ),

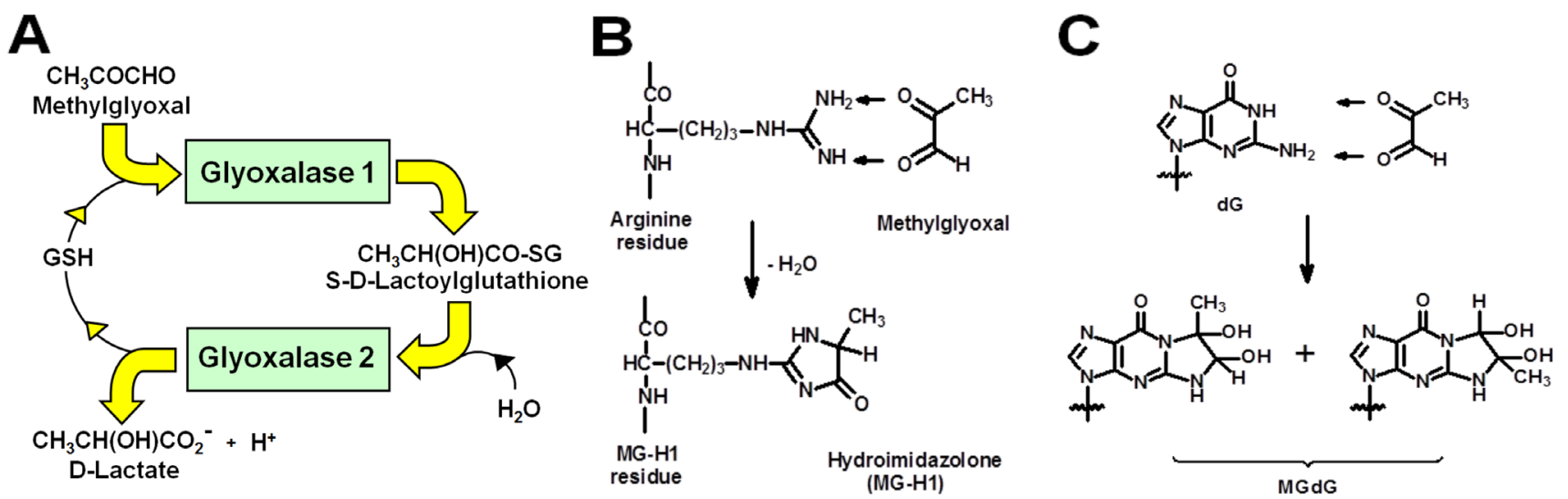

Figure 1: The glyoxalase metabolic pathway and prevention of glycation of protein and DNA by methylglyoxal. (A) Metabolism of MG by the glyoxalase system. (B) Protein modification by methylglyoxal with formation of arginine-derived hydroimidazolone, MG-H1. (C) DNA modification by methylglyoxal with formation of deoxyguanosine-derived imidazopurinone MGdG. The adduct residue is shown with guanyl base only. This figure is reproduced with permission from [55]. The major MG glycation adducts of protein and DNA are shown, accounting for $c a .90 \%$ of total adducts formed. Other minor adducts were described elsewhere [41, 56] 
and treatment with molecular targeted agents such as mammalian target of rapamycin (mTOR) inhibitors and tyrosine kinase inhibitors [13, 26-28]. However, response rates widely vary, with generally better response in patients with pancreatic as compared with midgut NET; and lack of objective response to chemotherapy in up to $60-70 \%$ of patients even with pNET [16, 21, 27, 29]. Various prospective predictive factors of tumour response have been proposed for other tumours, but information in patients with GEP-NET is limited and based on studies with relatively low numbers [30], also related to the low prevalence and heterogeneous nature of NET [31]. Identified factors include the proliferation index $\mathrm{Ki}-67 \%$, Akt, PTEN and thymidylate synthase for streptozotocinbased chemotherapy [30, 32]; and pAKT, PTEN, KRAS, FGFR4 mutations for treatment with mTOR inhibitors [33]. Here, we have analysed GLO1 CNV in a cohort of well characterised patients with GEP-NET who had received curative or debulking surgical treatment. Information about progression and survival was available for a mean $4.2 \pm 0.5$ years period.

\section{RESULTS}

\section{Patient characteristics}

Characteristics of included patients with suitable histological samples following surgical treatment are shown in Table 1. Data are presented separately for patients with pancreatic NET $(n=14)$ and midgut NET $(n=25)$.

\section{GLO1 copy number in neuroendocrine tumour tissue of patients with GEP-NET}

Previous estimation of GLO1 copy number in controls had shown the precision of GLO1 determination was (mean $\pm \mathrm{SD}): 2.00 \pm 0.13(\mathrm{n}=21)$. We therefore assumed copy number $>0.39$ (3 x SD, covering $99.7 \%$ of the probability) was significantly different from healthy control. In pooled analyses (pancreatic and midgut NET combined), GLO1 copy number was increased in GEPNET tissue, compared with surrounding healthy tissue. GLO1 copy number: mean 3.09, 95\% CI 2.52 - 3.66. Number of GEP-NET cases with change in GLO1 copy number, with respect to non-malignant tissue were: decreased GLO1 copy number, $\mathrm{n}=8$; unchanged GLO1 copy number, $\mathrm{n}=6$; and increased GLO1 copy number, $(\mathrm{n}=25) ; \mathrm{P}<0.001$, Kruskal-Wallis. Median [lower upper quartile] GLO1 copy number in these groups was: unchanged, 2.09 [1.91 - 2.23]; decreased, 1.15 [0.95 1.38], $\mathrm{P}<0.001$; and increased 3.46 [2.90 - 4.28], $\mathrm{P}<0.001$ (Figure 2A). Therefore, 64\% of GEP-NET had increased GLO1 copy number. For tumours with metastases, GLO1 copy number was not changed between primary and metastatic tumour: primary tumour, 3.00 [2.25 - 4.04]; metastatic tumour 3.55 [2.94 - 6.53], $\mathrm{n}=19$; Wilcoxon Signed Rank test (Figure 2B).

For pancreatic NET, there were 4 tumours with unchanged GLO1 copy number, 4 tumours had decreased GLO1 copy number and 6 had increased GLO1 copy number $(\mathrm{P}<0.001)$. In these groups, GLO1 copy number was: unchanged $2.05 \pm 0.28$, decreased $1.31 \pm 0.23$ $(\mathrm{P}<0.01)$, and increased $3.45 \pm 0.73(\mathrm{P}<0.01)$; t-test. Therefore, $43 \%$ of pancreatic NET had increased GLO1 copy number (Figure 2C). Metastatic tissue was available only from one patient with pancreatic NET, with a low GLO1 copy number of 0.82 . Two patients with pancreatic NET were excluded from survival and progression analyses due to early death after surgical intervention; one patient had a high GLO1 copy number in primary tissue (4.13) and one had a low GLO1 copy number (0.91).

For midgut NET, there were 4 tumours with unchanged GLO1 copy number, 3 tumours had decreased GLO1 copy number and 18 with increased GLO1 copy number $(\mathrm{P}<0.01)$. In these groups, GLO1 copy number was: unchanged $2.05 \pm 0.16$, decreased $1.03 \pm 0.35$ $(\mathrm{P}<0.01)$, and increased $4.18 \pm 1.89(\mathrm{P}<0.01)$; t-test. Therefore, $72 \%$ of midgut NET had increased GLO1 copy number (Figure 2D). For tumours with metastases, GLO1 copy number was not changed between primary and metastatic tumours. GLO1 copy number was: primary tumour, 3.16 [2.37 - 4.61], metastatic tumour 3.63 [3.22 - 7.06], $\mathrm{n}=18$; Wilcoxon Signed Rank test, $\mathrm{P}>0.05$. One patient with midgut NET had low GLO1 copy number of 1.24 in metastatic tissue (Figure 2E).

\section{Immunohistochemistry of glyoxalase 1 protein}

We could access further archived sample tissue for immunohistochemistry (IHC) analysis of Glo1 protein in tumour and non-tumour tissue in 29 cases; 7 pNET and 22 midgut NET. Tumour GLO1 copy number was increased, with respect to non-tumour tissue, in 19 of these cases. Glo1 Digital-IHC Score was associated positively with Glo1 IHC staining intensity Pathology Score. For Pathology scores 1 and 2 combined versus 3, Glo1 Digital-IHC Score (arbitrary units) were $1.61 \pm$ $0.33(\mathrm{n}=14)$ versus $2.08 \pm 0.55(\mathrm{n}=15)$, respectively; $\mathrm{P}<0.01$, t-test. Overall, there was no correlation of GLO1 copy with Glo1 Digital-IHC intensity in these NET cases. However, for cases showing increased Glo1 Digital-IHC Score in tumour versus non-tumour tissue, there was a positive correlation of change in Glo1 Digital-IHC Score with Glo1 copy number: $\mathrm{r}=0.62, \mathrm{P}=0.025$; Pearson $(\mathrm{n}$ $=13$ ). This was also found when cases were selected for increased Pathology Score: $\mathrm{r}=0.63, \mathrm{P}=0.016$; Pearson $(n=14)$.

\section{Progression free and overall survival}

The mean progression free survival was shorter in patients with pancreatic NET, compared with patients 
Table 1: Clinical characteristics of patients with GEP-NET

\begin{tabular}{|c|c|c|}
\hline Characteristic & Pancreatic NET & Midgut NET \\
\hline $\mathrm{n}$ & 14 & 25 \\
\hline Age (mean years; range) & $62.8(39-75)$ & $66.2(34-89)$ \\
\hline Sex (females/males) & $8 / 6$ & $13 / 12$ \\
\hline BMI $\left(\mathrm{kg} / \mathrm{m}^{2}\right)$ & $25.4(19.5-34.2)$ & $27.1(18.6-45.2)$ \\
\hline \multicolumn{3}{|l|}{ Tumour morphology } \\
\hline Well differentiated & $14(100 \%)$ & $25(100 \%)$ \\
\hline Poorly differentiated & $0(0 \%)$ & $0(0 \%)$ \\
\hline \multicolumn{3}{|l|}{ Tumour grade } \\
\hline Grade 1 & $8(57 \%)$ & $21(84 \%)$ \\
\hline Grade 2 & $5(36 \%)$ & $4(16 \%)$ \\
\hline Grade 3 & $1(7 \%)$ & \\
\hline \multicolumn{3}{|l|}{ Functioning status } \\
\hline Functioning $(\mathrm{n} / \%)$ & $1(7 \%)$ & $17(68 \%)$ \\
\hline Non-functioning (n/\%) & $13(93 \%)$ & $8(32 \%)$ \\
\hline \multicolumn{3}{|l|}{ Biomarkers } \\
\hline Serum chromogranin A (pmol/L) & $83.2 \pm 31.2$ & $296 \pm 103$ \\
\hline 24-h urine 5-HIAA ( $\mu \mathrm{mol} /$ collection $)$ & $\mathrm{n} / \mathrm{a}$ & $142 \pm 59$ \\
\hline \multicolumn{3}{|l|}{ Tumour stating } \\
\hline \multicolumn{3}{|l|}{ Tumour extent } \\
\hline $\mathrm{T} 1$ & $1(7.1 \%)$ & $0(0 \%)$ \\
\hline $\mathrm{T} 2$ & $3(21.4 \%)$ & $5(20 \%)$ \\
\hline $\mathrm{T} 3$ & $7(50.0 \%)$ & $11(44 \%)$ \\
\hline T4 & $3(21.4 \%)$ & $9(36 \%)$ \\
\hline \multicolumn{3}{|l|}{ Lymph node involvement } \\
\hline N0 & $8(57.1 \%)$ & $5(20 \%)$ \\
\hline N1 & $6(42.9 \%)$ & $20(80 \%)$ \\
\hline \multicolumn{3}{|l|}{ Systemic disease } \\
\hline M0 & $9(64.3 \%)$ & $9(36 \%)$ \\
\hline M1 & $5(35.7 \%)$ & $16(64 \%)$ \\
\hline \multicolumn{3}{|l|}{ Survival } \\
\hline Progression free survival (days) & $797 \pm 217$ & $1456 \pm 246$ \\
\hline Overall survival (days) & $1341 \pm 292$ & $1626 \pm 264$ \\
\hline
\end{tabular}

with midgut NET $(2.2 \pm 0.6$ versus $4.0 \pm 0.7$ years; $\mathrm{P}=$ $0.018)$; whereas overall survival was not significantly different between groups $(3.7 \pm 0.8$ versus $4.6 \pm 0.7$ years; $\mathrm{P}=0.51)$. In patients with midgut NET, time without progression was longer in patients with normal or low $(<$ 2.4 ) versus increased ( $\geq 2.4)$ GLO1 copy-number repeats [log Rank (Mantel-Cox), Chi square 5.629, $\mathrm{P}=0.018$ ] (Figure 3). In contrast, in patients with pancreatic NET, time without progression was not significantly different in patients with normal or low $(<2.4)$ versus increased $(\geq$ 2.4) GLO1 copy-number repeats [log Rank (Mantel-Cox), Chi square $0.582, \mathrm{p}=0.46]$. 
At the time of analysis, $6(15 \%)$ of the here investigated 39 patients with suitable histological samples and complete data had died of disease (Figure 3); of those, $2 / 25$ patients $(8 \%)$ died related to a midgut NET and $4 / 14$ patients $(29 \%)$ died related to a pancreatic NET, during a total observation period of up to11 years following surgical treatment of the NET.

\section{Correlation analyses}

There was no significant correlation of GLO1 copy number with Glo1 mRNA in primary GEP-NET tumours $(\mathrm{r}=0.20, \mathrm{p}=0.31)$. In patients with midgut NET, GLO1 copy number in metastatic tumour tissue strongly and significantly positively correlated with chromogranin A concentrations $(r=0.70 ; p=0.016)$, as measured directly before surgical treatment was performed; but a similar correlation of GLO1 copy number with chromogranin A in primary tumour tissue was absent $(r=0.27 ; p=0.35)$. In contrast, in patients with pancreatic NET there was a very strong negative correlation of preoperative chromogranin
A with GLO1 copy number in primary tumour tissue $(\mathrm{r}=-0.94, \mathrm{p}=0.005)$.

In the entire cohort, overall survival correlated with tumour stage $\mathrm{T}(\mathrm{r}=0.33, \mathrm{P}=0.042)$, but not with functioning status, staging according to nodal or systemic disease, type of surgery performed, tumour grade, age, BMI or sex (all $\mathrm{p}>0.11)$. There was a strong negative correlation of serum Chromogranin A concentrations with $\mathrm{BMI}(\mathrm{r}=-0.51 ; \mathrm{P}=0.022)$.

\section{Effect of glyoxalase 1 silencing on the growth of pancreatic neuroendocrine tumour BON1 cells in vitro}

To explore if Glo1 expression may be a factor influential in the effectiveness of chemotherapy of NETs, we studied the effect of Doxorubicin, a drug which has been used in combination with others for treatment of NETs - although it is not currently a preferred treatment option [38]. We used the BON1 cell line as an in vitro model and knocked down Glo1 expression by siRNA
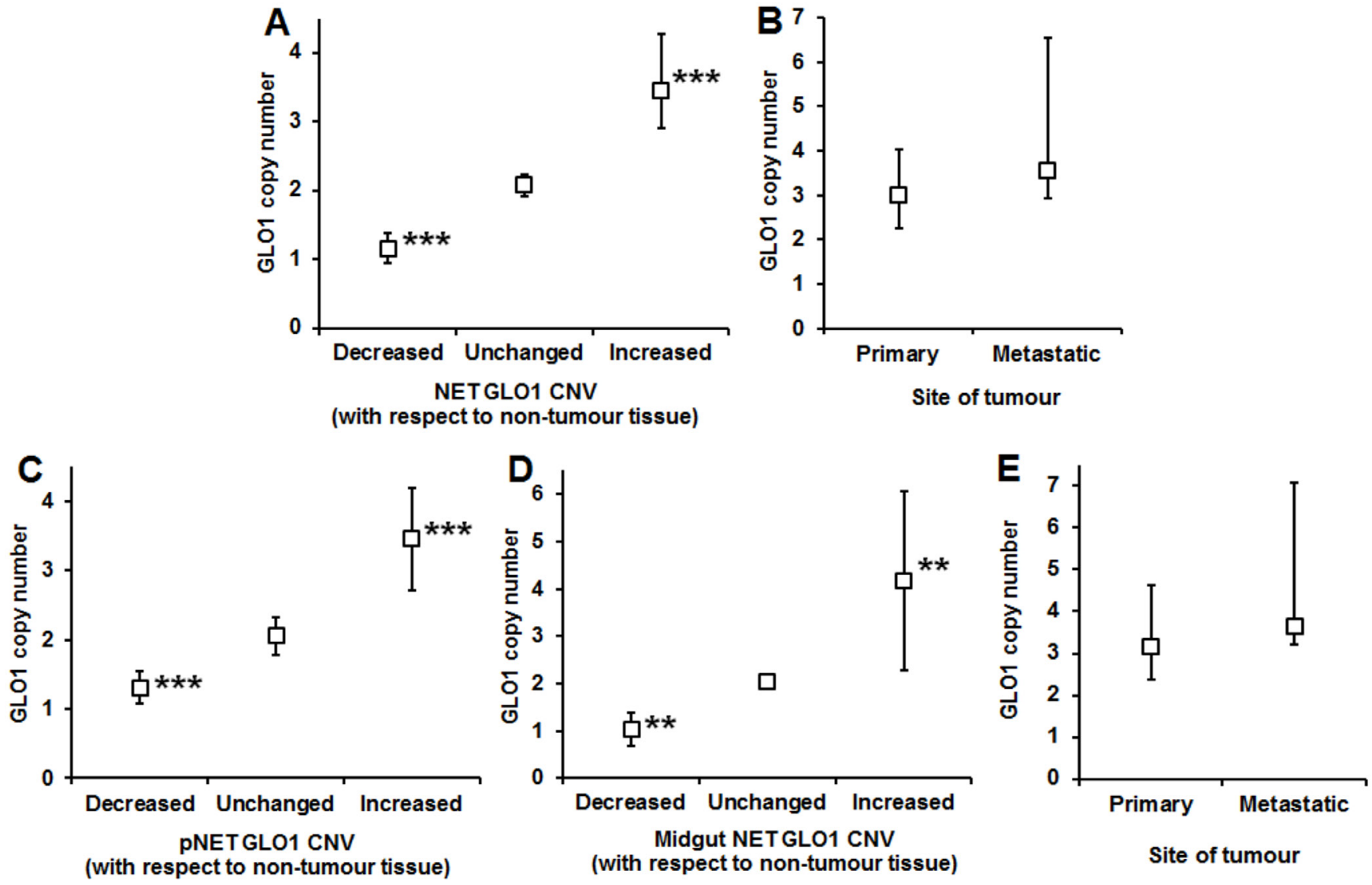

Figure 2: Change in GLO1 copy number in gastro-entero-pancreatic neuroendocrine tumours (GEP-NETs). (A) Change of GLO1 copy number in GEP-NETs. Data are median (lower - upper quartile); $\mathrm{n}=8$ (decreased), $\mathrm{n}=6$ (unchanged) and $\mathrm{n}=25$ (increased). (B) GLO1 copy number in GEP-NETs - comparison of primary and metastatic tumours. Data are median (lower - upper quartile); $\mathrm{n}=19$. (C) Change of GLO1 copy number in pNETs. Data are mean $\pm \mathrm{SD} ; \mathrm{n}=4$ (decreased), $\mathrm{n}=4$ (unchanged) and $\mathrm{n}=6$ (increased). (D) Change of GLO1 copy number in midgut NETs. Data are mean $\pm \mathrm{SD} ; \mathrm{n}=3$ (decreased), $\mathrm{n}=4$ (unchanged) and $\mathrm{n}=18$ (increased). (E) GLO1 copy number in midgut NETs - comparison of primary and metastatic tumours. Data are median (lower - upper quartile); $\mathrm{n}=18$. 
silencing. In control conditions, Doxorubicin inhibited the Growth of BON1 cells: $\mathrm{GC}_{50}=3.06 \pm 0.13 \mu \mathrm{M}$ and $\mathrm{n}=$ $2.23 \pm 0.20$. Glo1 silencing potentiated the inhibition of BON1 cell growth by Doxorubicin: with Glo1 silencing, $\mathrm{GC}_{50}=1.16 \pm 0.13 \mu \mathrm{M}$ and $\mathrm{n}=1.61 \pm 0.13$. Glo1 silencing alone also decreased BON1 cell growth by $27 \pm 2 \%$ (n $=3, \mathrm{P}<0.001)$ under the siRNA transfection conditions described (Figure 4).

\section{DISCUSSION}

We present herein the first report of GLO1 copy number variation in GEP-NET and the finding of high prevalence of increased GLO1 copy number - particularly of midgut NETs. Increased GLO1 copy number appeared to be clinically functional through link to increased tumour progression in midgut NET.

Increased GLO1 copy number was previously found in other human tumours where the highest prevalence was in breast cancer, small cell lung cancer and nonsmall cell lung cancer [21]. Here, we show that in our cohort of patients with well differentiated GEP-NET, the frequency of increased GLO1 copy number was markedly higher than in other tumours investigated to date, with prevalences of $43 \%$ in pancreatic NET and $72 \%$ in midgut NET, respectively. Comparable GLO1 copy number in metastatic and primary tumour indicated that increased
GLO1 copy number, once acquired by the GEP-NET, was maintained. Moreover, increased GLO1 copy number was associated with a significantly shorter time to tumour progression in patients with midgut NET. Increased GLO1 copy number and related expression has previously been considered permissive for tumour growth with high flux of glycolysis and hence flux of formation of MG [3] and also resistance to cancer chemotherapy [8]. We also found decreased GLO1 copy number in $29 \%$ of pancreatic NET and $12 \%$ midgut NET. This may be due to GLO1 allele deletion or tumour genetic instability; or DNA damage in sample processing, thereby disrupting binding of primers for qPCR.

The observation in our study that Glol mRNA expression did not significantly correlate with GLO1 copy number was possibly related to sample size and poor efficiency of mRNA extraction from available FFPE tissue blocks, which is a limitation of this study. Most mRNA and other long RNAs are fragmented during formalin fixed, paraffin-embedded (FFPE) tissues [39]. However, in more than $80 \%$ of the respective cases with higher GLO1 copy number, mRNA expression was increased as well. Importantly, in a genome wide copy number variation analysis, GLO1 copy number was among only 3 genes out of 600 investigated where consistently increased gene expression was confirmed in all investigated tissues [18], supporting that GLO1 copy number increases are functional.

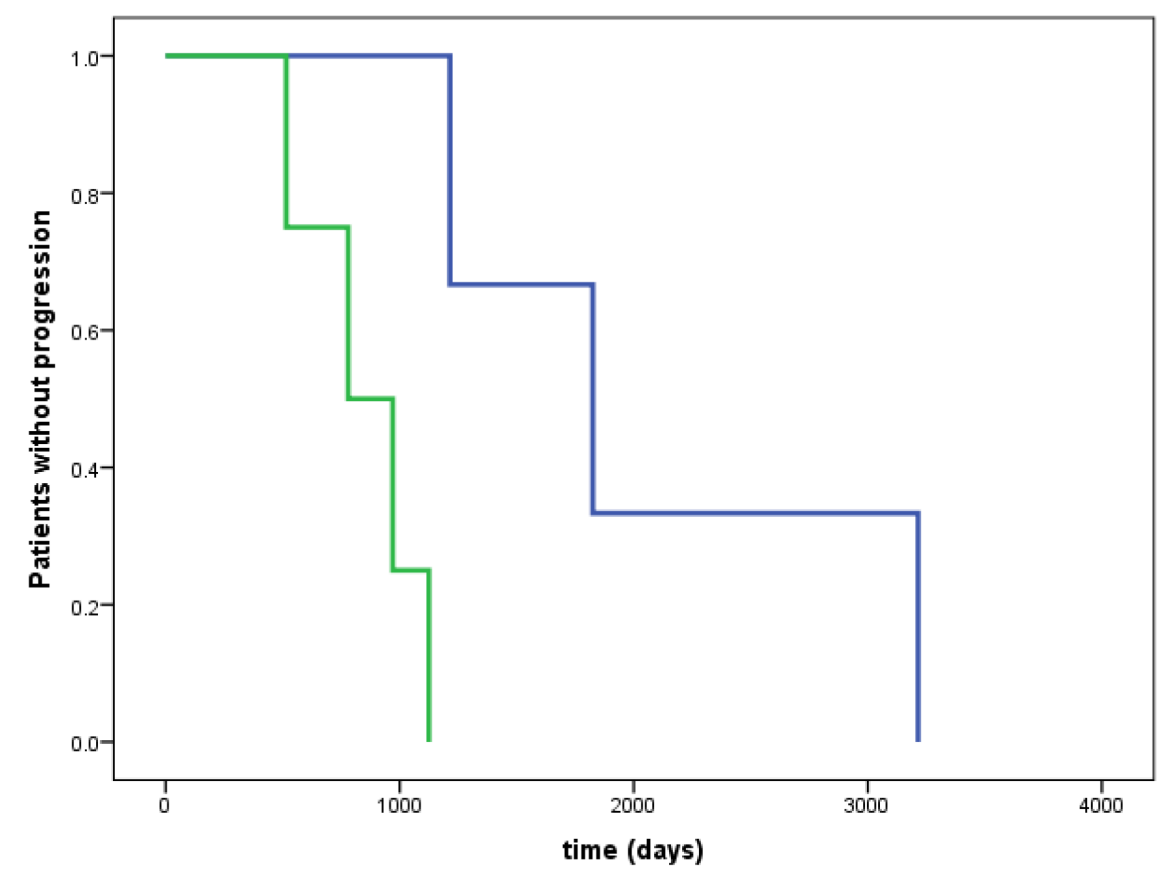

Figure 3: Time without progression in patients with midgut NET. Time without progression was significantly longer in patients with normal or low $(<2.4)$ versus increased $(\geq 2.4)$ GLO1 copy number [log Rank (Mantel-Cox), Chi square 5.629, $\mathrm{p}=0.018$ ]. No significant difference in time without progression was observed in patients with pancreatic NET [ $\log$ Rank (Mantel-Cox), Chi square 0.582, $\mathrm{p}=0.46]$. Blue line: GLO1 copy number $<2.4$; green line: GLO1 copy number $\geq 2.4$. 
Extraction of DNA and protein from FFPE tissue sections is more efficient than for RNA and we therefore sought evidence of association of GLO1 copy number with Glo1 protein in NET tissue by immunohistochemical analysis. Although there was no overall correlation of Glo1 Digital-IHC Score with Glo1 copy number, in patients where Glo1 Digital-IHC Score was higher than in related non-tumour tissue, the increase in Glo1 DigitalIHC Score correlated positively with GLO1 copy number where selection was made by either Glo1 Digital-IHC Score of the stained tissue section or by expert pathologist assessment. The correlation coefficient values, $0.62-0.63$, suggesting that GLO1 copy number accounts for $c a$. $40 \%$ of the variation in Glol expression. Therefore, where there is increase in Glo1 expression in NETs, GLO1 copy number increase appears to be an influential factor.

Increased GLO1 copy number is likely a negative survival factor in NETs through its mediation of overexpression of Glo1. The latter is permissive for growth of tumours with high glycolytic rate and related high flux of potentially cytotoxic MG [3]. The clinical treatment of patients in this study was by surgical resection of the primary NET. Residual primary and metastatic tumours with the growth advantage of Glo1 overexpression may impact negatively and markedly so on survival. The mechanism of GLO1 copy number increase in NETs is unknown. Our recent studies suggest it may be driven by hypoxia-activated histone demethylase $K D M 4 A / J M J D 2 A$. Increased histone demethylation is hypothesised to create more open chromatin which promotes inappropriate recruitment of mini-chromosome maintenance (MCM) proteins and DNA polymerases and thereby facilitate re-replication of genomic DNA for copy number gain as recently described [11]. KDM4A is highly expressed in many tumours where it is also involved in metabolic reprogramming for increased tumour anaerobic glycolysis [40].

It might be expected that increased Glo1 expression in NETs would be associated with decreased levels of protein and DNA glycation adducts. This applies, however, if there is no proportionate or disproportionate increase in flux of MG in NETs - as indicated by metabolic modelling of the glyoxalase pathway [27]. Previous experimental studies suggest that tumour cell lines with high GLO1 copy number and Glo1 expression have high glycolytic rate, high flux of $\mathrm{MG}$ formation and relatively high content of DNA glycation adducts [3, 21]. This likely reflects an imperfect adaptation of tumour cells with high glycolytic activity to suppress increased MG concentration and potential cytotoxicity. MG adducts of protein and DNA cannot be reliably assessed in FFPE tissue samples as the preservation and analyte extraction procedures

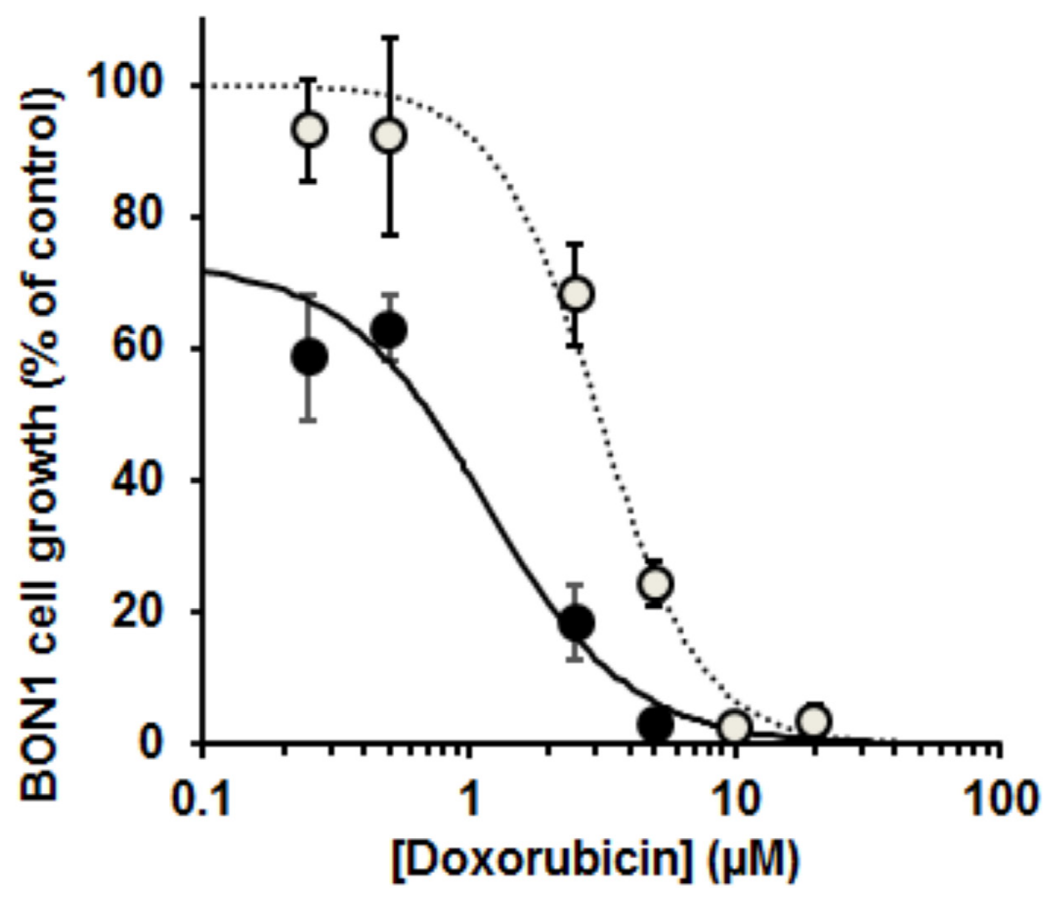

Figure 4: Effect of doxorubicin on the growth of the pancreatic neuroendocrine tumour cell line and effect of silencing of glyoxalase 1. Doxorubicin concentration-response curve for BON1 cell growth in vitro. Key: open symbols and dotted line, wildtype Glo1 expression; filled symbols and solid line, BON1 cells with Glo1 silencing. Data are mean \pm SEM, $\mathrm{n}=3$ for Doxorubicin concentrations $0.25,0.50,2.5,5,10$ and $20 \mu \mathrm{M}$. Dose-response curve equations given are: wild-type Glo1 expression, BON1 cell growth $(\%$ of control $)=100 \times 3.06^{2.23} /\left(3.06^{2.23}+[\text { Doxorubicin }]^{2.23}\right)$; and with Glo1 silencing - BON1 cell growth $(\%$ of control $)=73 \times 1.16^{1.61} /$ $\left(1.16^{1.61}+[\text { Doxorubicin }]^{1.61}\right)$. 
compromise the assays [3, 41]. MG protein and DNA adducts may be assessed in NETs in future studies when suitable frozen tumour samples have been accumulated.

To assess the likely functionally of Glol expression in chemotherapy of NETs, we studied the effect of doxorubicin, a drug that has been used in combination with others for the treatment of NETs [42], on the growth of pancreatic NET cell line, BON1. Silencing of Glo1 potentiated the growth inhibitory effect of doxorubicin on BON1 cells and, moreover, also decreased BON1 cell growth in the absence of drug treatment. This suggests that Glol expression may be a factor linked to resistance of NETs to doxorubicin and likely other anticancer drugs. GLO1 may also suppress cytotoxicity of STZ and cause MDR in chemotherapy of pancreatic NET. Cell permeable Tat-Glo1 protein prevented STZ-induced toxicity to pancreatic beta-cells [43]. Glo1 overexpression was linked to MDR in cancer chemotherapy of other tumour types $[8,12]$. Where Glol overexpression was found, resistance to cytotoxicity could be overcome by siRNA silencing of Glo1 or inhibition by cell permeable Glo1 substrate analogue inhibitor [12, 21, 44, 45]. Further studies of anticancer drugs with low sensitivity to Glo1-mediated MDR for chemotherapy of NETs may now be considered. The mechanism of Glo1-mediated MDR is likely the suppression of MG-induced apoptosis contributing to the mechanism of action of anticancer drugs - as recently reviewed [11].

A potential role of GLO1 as a predictive factor for both tumour progression and response to treatment could be of particular interest, considering that GLO1 is the most frequently amplified gene in numerous human cancer cell lines [21], with additional GLO1 copies typically being functional $[21,27,29]$.

We also found that in patients with midgut NET, a low GLO1 copy number was associated with increased time to tumour progression, thereby possibly representing an independent prognostic factor. A similar effect in patients with pancreatic NET was absent. These results further support the view that pancreatic NET have distinct characteristics as compared with midgut NET, with known differences in both treatment response and overall survival between these types of neuroendocrine malignancies [42, 46-48].

Incidence of NET has $4-5$ fold increased in Westernized countries from 1973 - 2007, with incidence influenced by age, gender, ethnicity and geographic location [49]. A family history of cancer was a significant risk factor for all NETs. In a USA-based study, a long-term history of diabetes mellitus was a risk factor for midgut NETs (adjusted odds ratio $[\mathrm{AOR}]=5.6$ ), particularly in women $(\mathrm{AOR}=8.4)$. Diabetes increased this risk 6-fold in women to $\mathrm{AOR}=52.2$ [50]. There has recently been intense interest in the increased cancer risk in patients with diabetes. The increase in relative risks associated with diabetes are greatest ( $\geq 2$-fold) for cancers of the liver, pancreas and endometrium [51]. Midgut NET in women appear to also be in this grouping. In the pre-malignant state, Glo1 is a tumour suppressor protein [7], which is likely mediated through suppression of MG modifications of DNA and associated mutagenesis. Diabetes is associated with tissue-specific down regulation of Glo1 and increased MG [52], which may increase risk of NET tumourigenesis. Hyperinsulinemia in type 2 diabetes is also associated with an increase of both estrogen and testosterone in women but not in men - which stimulates cell proliferation and decreases apoptosis [53]. Once malignant transformation is established in NETs, the increased Glo1 activity of NETs may provide a growth advantage that underlies the association of increased GLO1 copy number with poor survival.

Further investigations of the clinical impact of GLO1 copy number in patients with GEP-NET will require multicentre studies with relevant numbers of patients who ideally had surgical on repeated occasions; and patients with surgical samples from tumour resection and subsequent treatment with STZ-based chemotherapy, mTOR inhibitors or tyrosine kinase inhibitors in case of a future relapse or progression. Neoadjuvant chemotherapy for patients with advanced pancreatic NET aiming at tumour downsizing before surgical resection has been recently proposed as well [54] and may provide further opportunities for future research. However, even if a relevant number of cases could be achievable in a large international multi-centre setting, results of GLO1 CNV may be influenced by not rarely observed changes in tumour biology of GEP-NET in the chronic setting, and by influences of the treatment with cytotoxic agents per se, i.e. by increasing cellular $\mathrm{MG}$ concentrations and related cytotoxicity as part of their mechanism of action $[12,21$, 26].

In further studies it will be important to confirm and corroborate the findings of increased GLO1 copy number in patients with GEP-NET with a related paralogue ratio test and also, in selected samples, examine whether the genetic domain increased in copy number is similar to that found in other tumours, using high intensity genomewide DNA microarray analyses [21, 29]. With increased patient numbers and long term ( $>10$ years) follow-up, the association of increased GLO1 copy number and expression with rapid progression may be evaluated in a case-control study. The current study suggests that overexpression of Glo1 through increased GLO1 gene copy number in patients with GEP-NET may facilitate rapid progression and resistance to therapy - assuming a role as it does in other tumour types of mediator of MDR.

In conclusion, increased GLO1 copy number was a very common molecular pathological event in patients with GEP-NET. Measuring GLO1 copy number may provide a novel predictive marker to assess the response to treatment in systemic disease. 


\section{MATERIALS AND METHODS}

Samples for analyses were identified from the GEPNET database in the ARDEN NET Centre, University Hospitals Coventry and Warwickshire (UHCW) NHS Trust, European Neuroendocrine Tumour Society (ENETS) Centre of Excellence. Ethics approval had been obtained from the ARDEN Tissue Bank, Application for Biomaterials (ATB15-004; July 2015; UHCW ethics approval 12/SC/0526). Formalin fixed paraffin embedded (FFPE) tissue blocks from surgical resection of primary tumours and surrounding healthy tissue were available from procedures performed between 2005 and 2015. Only samples with both available tumour tissue and healthy surrounding tissue were selected for analyses. In mixed sections, separate cuts from FFPE tissue blocks were provided for the purpose of the analyses. The respective area of tumour and healthy tissue was determined by a Consultant Histopathologist with extensive experience in GEP-NET and clearly labelled for further analysis. A total of 290 sections and 348 scrolls was received. Two patients with pancreatic NET who died early $(<10$ days) after Whipple's procedure were excluded, given the impact on progression and survival analyses. All patients had well differentiated GEP-NET grade 1 or grade 2 GEP-NET, with the exception of one patient with pancreatic NET who had a grade 3 (Ki-67 proliferation index 25\%) but also well differentiated tumour. The baseline characteristics of the included patients (pancreatic NET; $n=14$; midgut NET, $n=25$ ) are given in Table 1.

\section{DNA and RNA extraction from tissue sections}

DNA extraction from FFPE sections For DNA extraction, 2 pieces of $7 \sim 10 \mu \mathrm{m}$ section scrolls were cut in each block. For tissue sections received in binding on slides, the healthy tissue and tumour tissue was manually scraped respectively in a $1.5 \mathrm{ml}$ Eppendorf tube containing $500 \mu \mathrm{l}$ of $100 \%$ ethanol. After centrifugation at $17,000 \mathrm{~g}$ for $10 \mathrm{~min}$ at room temperature, the supernatant was discarded and open tubes were left in $37^{\circ} \mathrm{C}$ for ethanol to evaporate to dryness. Samples were then incubated twice at $65^{\circ} \mathrm{C}$ for 15 min with $1 \mathrm{ml}$ of xylene to dissolve and remove paraffin and two washes with $100 \%$ ethanol to remove residual xylene and left to dry. DNA was extracted with Qiagen DNeasy ${ }^{\circledR}$ Blood \& Tissue Kit. The quantity and quality of DNA extraction samples were evaluated with NanoDrop 1000 and stored the DNA at $-20^{\circ} \mathrm{C}$ until further use.

RNA extraction from FFPE sections For each FFPE block, 3 pieces of 7 10 $\mu \mathrm{m}$ section were cut with a microtome and stored in the DNase and RNase free tubes at $4^{\circ} \mathrm{C}$ until extraction of total RNA. Total RNA was extracted with PureLink FFPE RNA Isolation Kit (Invitrogen) and performed according to the manufacturer's instructions. Briefly, sectioned FFPE tissue deparaffinised with melting buffer and incubated at $72^{\circ} \mathrm{C}$ for $10 \mathrm{~min}$ to melt paraffin. Sections were then digested with proteinase $\mathrm{K}$ at $60^{\circ} \mathrm{C}$ for $4 \mathrm{~h}$ and centrifuged (17,000 g, $10 \mathrm{~min}$, room temperature) to sediment nodigested tissue and separate paraffin. The supernatant, tissue lysate, was transferred to a new tube and $400 \mu \mathrm{l}$ binding buffer and $800 \mu 1$ 100\% ethanol added. The tissue lysate was further processed by selective binding of RNA to a silica-based membrane in a microspin column. Total RNA isolation and purification were performed with thorough washing with buffer and RNA eluted in RNasefree water. The RNA quality and quantity were determined with NanoDrop 1000 and stored the RNA at $-80^{\circ} \mathrm{C}$ until further use.

Both DNA and RNA extraction yielded good quantity and quality of nucleic acid. For pNET, RNA and genome DNA in 17 cases out of 18 cases were successfully extracted and in midgut NET, all extractions from the FFPE samples were successful.

\section{mRNA analysis with quantitative real-time polymerase chain reaction (qRT-PCR)}

Reverse transcriptase reaction was performed in 20 $\mu 1$ total volume with $500 \mathrm{ng}$ total RNA with High-Capacity cDNA Reverse Transcription Kit (Applied Biosystems ${ }^{\mathrm{TM}}$ ) and run using an Eppendorf Mastercycler gradient. The reaction was incubated at $25^{\circ} \mathrm{C}$ for $10 \mathrm{~min}$, then $37^{\circ} \mathrm{C}$ for $2 \mathrm{~h}$, and then $85^{\circ} \mathrm{C}$ for $5 \mathrm{~min}$. After 3 -fold dilution, reverse transcription product cDNA $(2 \mu \mathrm{l})$ was used for qRTPCR to detect target gene expression level with TaqMan technique on ABI 7500 real time PCR system in $20 \mu \mathrm{l}$ of reaction volume. The initial reaction was at $95^{\circ} \mathrm{C}$ for 10 min, followed by 40 cycles at $95^{\circ} \mathrm{C}$ for $15 \mathrm{~s}$ and $60^{\circ} \mathrm{C}$ for $1 \mathrm{~min}$. The primers and probe for Glol and ACTB were pre-designed primers probe mixture from Life Technology Ltd (Paisley, Scotland). Gene expression level was evaluated using $2^{\text {(-ddCt) }}$ with ACTB as a reference gene for normalization for relative expression level. Analyses were performed in triplicate. Values are presented as the relative expression of the target gene in tumor tissue compared to healthy tissue.

\section{Real-time quantitative PCR for GLO1 copy number estimation}

Real-time Quantitative PCR was performed using TaqMan ${ }^{\circledR}$ Copy number assays protocol (Applied Biosystems). The PCR reaction contained: genomic DNA (20 ng), 2x concentrated TaqMan master mix $(10 \mu \mathrm{l})$, $20 x$ primer-probe working mixture for target gene GLO1 and reference gene RNase $\mathrm{P}(1 \mu \mathrm{l})$ in $20 \mu \mathrm{l}$ total reaction volume. The PCR reaction was performed with an ABI 7500 real time PCR system. The cycle conditions were: initial cycle, $95^{\circ} \mathrm{C}$ for $2 \mathrm{~min}$, with following 40 cycles at $95^{\circ} \mathrm{C}$ for $15 \mathrm{~s}$ and $60^{\circ} \mathrm{C}$ for one min. PCR Reactions were performed in quadruplicate for each sample. The 
copy number for each sample was calculated with $2^{\text {(-ddCt) }}$ method and the GLO1 copy number in cancer tissue was referenced to healthy tissue assuming GLO1 copy number 2.00. From analysis of GLO1 copy number in the healthy human population, qPCR analysis gave GLO1 copy number $2.00 \pm 0.13(n=21)$. GLO1 copy number outside of the interval mean $\pm \mathrm{SD}, 1.61-2.39$, was considered to be significantly different from the normal control 2.00 copies.

\section{Tissue immunohistochemistry of glyoxalase 1 protein}

Tissue sections $(5 \mu \mathrm{m})$ of tumour and healthy tissue were cut from formalin-fixed paraffin-embedded (FFPE) tumour and healthy tissue block with a microtome. Sections were immersed in xylene (3 x $5 \mathrm{~min})$, isopropanol ( 2 x $2 \mathrm{~min}), 70 \%$ (v/v) isopropanol/water (1 x $2 \mathrm{~min}$ ), and finally rinsed for 2 mins in water. Antigen recovery in the sections was performed with 2100 Antigen Retriever $^{\mathrm{TM}}$ antigen-retrieval buffer (Aptum Biologics Ltd, Southampton, UK) in $10 \mathrm{mM}$ sodium citrate, $0.05 \%$ Tween-20, $\mathrm{pH}$ 6.0, according to the manufacturer's instructions. After antigen-retrieval procedure, the slides were rinsed with distilled water $(2 \times 5 \mathrm{~min})$. For Glo1 immunostaining, VECTASTAIN Elite ABC (Rabbit IgG) Kit (Vector Laboratories, Peterborough, U.K.) was used and following the manufacture's user manual. Briefly, sections pre-treated with BLOXALL Endogenous Peroxidase and Alkaline Phosphatase Blocking Solution to block endogenous peroxidase activity for $10 \mathrm{~min}$ at room temperature. After washing with tris-buffered saline (250 mM Tris, $27 \mathrm{mM} \mathrm{KCl,} 1.37 \mathrm{M} \mathrm{NaCl}, \mathrm{pH} 7.4$, and 1\% Triton X-100; TBST), serum blocking solution was added to sections and incubated at room temperature for $20 \mathrm{~min}$. Excess solution was removed by blotting with filter paper and the sections were incubated with 1:3000 diluted rabbit anti-human GLO1 antibody [34] at $4^{\circ} \mathrm{C}$ overnight. Slides were then washed with TBST, immersed in biotinylatedanti-human IgG and incubated at room temperature for $30 \mathrm{~min}$. The slides were then washed in PBS, immersed in peroxidase substrate solution, 3,3'-diaminobenzidine (DAB; DAB substrate kit, Abcam, Cambridge) at room temperature $7 \mathrm{~min}$, rinsed with water and then with phosphate buffered Tween (10 mM sodium phosphate, $0.15 \mathrm{M} \mathrm{NaCl}, 0.05 \%$ Tween $^{\text {TM }} 20, \mathrm{pH}$ 7.5; PBS-Tween). Slides were counter-stained with Meyer's haematoxylin (Sigma) for $60 \mathrm{~s}$, rinsed in water and then PBS-Tween. The slides were passed through water, 90\% EtOH, 100\% EtOH and xylene (2 min each) and mounted in DPX solution (Sigma).

The stained slides were assessed by an experienced pathologist (G.K.) and scored for weak, moderate and intense Glo1 immunostaining; scores of 1,2 and 3, respectively. We also digitised the histology slides using the Mirax Midi ${ }^{\mathrm{TM}}$ slide scanner (Carl Zeiss MicroImaging GmbH, Jena, Germany). Tissue regions on the digital slides were identified using an entropy based segmentation approach and visual fields containing DAB reactivity above a threshold were selected automatically. This was done to ensure that the automated scoring was restricted to tissue segments containing DAB reactivity only. For antigen quantification, we first digitally reconstructed separate channels for the Haematoxylin and DAB stains in the Optical Density space [35]. Automated quantification of antigen intensity then proceeded as follows [36]: a. Stain intensity was estimated from the DAB channel; and b. Statistics from all selected visual fields in the slide were combined to represent an overall measure (score) for Glo1 protein - referred to as "Digital-IHC Score" below.

\section{Culture of BON1 pancreatic neuroendocrine tumour cell line, sensitivity to doxorubicin and Glo1 silencing}

The BON1 cell line was kindly supplied by Professor Courtney Townsend Jr. (University of Texas Medical Branch, Galveston, TX, USA). BON1 cells were derived from a metastatic human carcinoid tumour of the pancreas and are used as a model of pNET cells. BON1 cells were cultured in Dulbecco's Modified Eagle Medium/ Nutrient Mixture F-12 (DMEM/F12) medium containing $2.5 \mathrm{mM}$ L-glutamine, 1:1 (v/v; Thermo Fisher Scientific), supplemented with $5 \%$ fetal bovine serum (Sigma) and $1 \%$ penicillin/streptomycin (Sigma, Poole, Dorset, U.K.) and incubated in $5 \% \mathrm{CO}_{2}$ humidified atmosphere at $37^{\circ} \mathrm{C}$.

BON1 cells $\left(4 \times 10^{4}\right)$ were seeded in 48 -well plates. After culture overnight, cells were transfected with 25 nM Accell Human GLO1 SMART siRNA pool or an Accell non-targeting Control siRNA pool (GE Healthcare Dharmacon Inc, Little Chalfont, Buckinghamshire, U.K.) with Lipofectamine ${ }^{\circledR}$ RNAiMAX Transfection Reagent (Thermo Fisher Scientific, Paisley, U.K.) based on the manufacture's protocol. Glo1 silencing was confirmed by assay of Glo1 mRNA which was decreased $>95 \%$. After 72 hours of transfection, the cells were incubated with and without $0.25-20 \mu \mathrm{M}$ doxorubicin. The stock solution of doxorubicin was $10 \mathrm{mM}$ in DMSO such that the maximum exposure to DMSO was $0.2 \%$. Cell growth was assessed by the 3-(4,5-dimethylthiazol-2-yl)-2,5diphenyltetrazolium bromide (MTT) method [37]. Data were fitted by non-linear regression to the doxorubicin concentration-response equation, $\mathrm{A}_{570, \text { Drug }} / \mathrm{A}_{570, \text { Control }}=100$ x $\mathrm{GC}_{50}{ }^{n} /\left(\mathrm{GC}_{50}{ }^{\mathrm{n}}+\right.$ [Doxorubicin] $\left.{ }^{\mathrm{n}}\right)$, solving for $\mathrm{GC}_{50}$ and $\mathrm{n}$ where $\mathrm{A}_{570, \text { Drug }} / \mathrm{A}_{570, \text { Control }}$ is the absorbance at $570 \mathrm{nM}$ in MTT incubated extracts from cell incubations with and without the anticancer drug, $\mathrm{GC}_{50}$ is the median growth inhibitor concentration and $\mathrm{n}$ is the logistic regression coefficient. 


\section{Statistical analyses}

Data are presented as mean $\pm \mathrm{SD}$. Continuous variables were tested for parametric distribution using the Kolmogorov-Smirnov test. Significance of mean and median between different groups was evaluated using Student's t test and Mann-Whitney U test, respectively, and significance of difference of medians of variables of tumours at primary and metastatic sites of the same donor were analysed by Wilcoxon's Signed Rank test. KruskalWallis test was used for comparing ordinal or nonnormally distributed variables for more than two groups. For nominally scaled variables, Chi-square tests were applied. Correlation analyses were perfomed by Pearson and Spearman methods for parametric and nonparametric data distributions, respectively. Progression free survival was measured from the time of surgical treatment to progression according to RECIST criteria, death or last follow up. Overall survival was measured from the time of surgical treatment to death. Kaplan Meier survival analyses were performed and differences in survival or time to progression were estimated using log rank tests. A p value $<0.05$ was considered statistically significant. Data analyses were performed using IBM SPSS Statistics version 22 (Chicago, Illinois, USA).

\section{Abbreviations}

GLO1, glyoxalase-1 gene; GEP-NET, gastro-enteropancreatic neuroendocrine tumour; $\mathrm{MG}$, methylglyoxal; $\mathrm{CNV}$, copy number variation; MDR, multidrug resistance; STZ, streptozotocin; mTOR, mammalian target of rapamycin; FFPE, formalin fixed, paraffin embedded; IHC, immunohistochemistry.

\section{Author contributions}

MOW and PJT designed the study. MX and AS performed the biochemical analyses. SJ, AF and $\mathrm{KG}$ provided and processed the histological samples. GD provided support with data collection. GK and NR provided intellectual input for discussion of data. MOW performed data collection, statistical analyses and drafted the first version of the manuscript. MOW and PJT wrote the manuscript and all co-authors approved it. MOW is the guarantor if the study.

\section{ACKNOWLEDGMENTS}

We thank Andrew White, tissue bank Biomedical Assistant UHCW, for support with processing of the samples; and Josi Goodby, Clinical Trials Practitioner, for support with data collection. TQ conducted the experiments for Digital-IHC scoring under supervision of NR. We thank Professor Courtney Townsend Jr. (University of Texas Medical Branch, Galveston, TX, USA) for supply of the BON1 cell line.

\section{CONFLICTS OF INTEREST}

The authors confirm that there were no conflicts of interest.

\section{FUNDING}

This study was supported by a grant to MOW, Lead of the ARDEN NET Centre ENETS Centre of Excellence, from the Research \& Development Department, UHCW.

\section{REFERENCES}

1. Rabbani N, Thornalley PJ. Dicarbonyl stress in cell and tissue dysfunction contributing to ageing and disease. Biochem Biophys Res Commun. 2015; 458: 221-6.

2. Ahmed N, Dobler D, Dean M, Thornalley PJ. Peptide mapping identifies hotspot site of modification in human serum albumin by methylglyoxal involved in ligand binding and esterase activity. J Biol Chem. 2005; 280: 5724-32.

3. Thornalley PJ, Waris S, Fleming T, Santarius T, Larkin SJ, Winklhofer-Roob BM, Stratton MR, Rabbani N. Imidazopurinones are markers of physiological genomic damage linked to DNA instability and glyoxalase 1-associated tumour multidrug resistance. Nucleic Acids Res. 2010; 38: 5432-42.

4. Rabbani N, Thornalley PJ. Dicarbonyl proteome and genome damage in metabolic and vascular disease. Biochem Soc Trans. 2014; 42: 425-32.

5. Karachalias N, Babaei-Jadidi R, Rabbani N, Thornalley PJ. Increased protein damage in renal glomeruli, retina, nerve, plasma and urine and its prevention by thiamine and benfotiamine therapy in a rat model of diabetes. Diabetologia. 2010; 53: 1506-16.

6. Thornalley PJ, Battah S, Ahmed N, Karachalias N, Agalou S, Babaei-Jadidi R, Dawnay A. Quantitative screening of advanced glycation endproducts in cellular and extracellular proteins by tandem mass spectrometry. Biochem J. 2003; 375: 581-92.

7. Zender L, Xue W, Zuber J, Semighini CP, Krasnitz A, Ma B, Zender P, Kubicka S, Luk JM, Schirmacher P, McCombie WR, Wigler M, Hicks J, et al. An oncogenomics-based in vivo RNAi screen identifies tumor suppressors in liver cancer. Cell. 2008; 135: 852-64.

8. Sakamoto H, Mashima T, Kizaki A, Dan S, Hashimoto Y, Naito M, Tsuruo T. Glyoxalase I is involved in resistance of human leukemia cells to antitumor agent-induced apoptosis. Blood. 2000; 95: 3214-8.

9. Dobler D, Ahmed N, Song L, Eboigbodin KE, Thornalley PJ. Increased dicarbonyl metabolism in endothelial cells in hyperglycemia induces anoikis and impairs angiogenesis by RGD and GFOGER motif modification. Diabetes. 2006; 55: 1961-9.

10. Kang Y, Edwards LG, Thornalley PJ. Effect of methylglyoxal on human leukaemia 60 cell growth: 
modification of DNA G1 growth arrest and induction of apoptosis. Leuk Res. 1996; 20: 397-405.

11. Rabbani N, Xue M, Weickert MO, Thornalley PJ. Multiple roles of glyoxalase 1-mediated suppression of methylglyoxal glycation in cancer biology-Involvement in tumour suppression, tumour growth, multidrug resistance and target for chemotherapy. Seminars in Cancer Biology. 2017.

12. Sakamoto H, Mashima T, Sato S, Hashimoto Y, Yamori T, Tsuruo T. Selective activation of apoptosis program by S-pbromobenzylglutathione cyclopentyl diester in glyoxalase I-overexpressing human lung cancer cells. Clin Cancer Res. 2001; 7: 2513-8.

13. Rabbani N, Thornalley PJ. The glyoxalase system--from microbial metabolism, through ageing to human disease and multidrug resistance. Semin Cell Dev Biol. 2011; 22: 261.

14. Tripodis N, Mason R, Humphray SJ, Davies AF, Herberg JA, Trowsdale J, Nizetic D, Senger G, Ragoussis J. Physical map of human 6p21.2-6p21.3: region flanking the centromeric end of the major histocompatibility complex. Genome Res. 1998; 8: 631-43.

15. Ranganathan S, Ciaccio PJ, Walsh ES, Tew KD. Genomic sequence of human glyoxalase-I: analysis of promoter activity and its regulation. Gene. 1999; 240: 149-55.

16. Redon R, Ishikawa S, Fitch KR, Feuk L, Perry GH, Andrews TD, Fiegler H, Shapero MH, Carson AR, Chen W, Cho EK, Dallaire S, Freeman JL, et al. Global variation in copy number in the human genome. Nature. 2006; 444: 444-54.

17. Wong KK, deLeeuw RJ, Dosanjh NS, Kimm LR, Cheng Z, Horsman DE, MacAulay C, Ng RT, Brown CJ, Eichler EE, Lam WL. A comprehensive analysis of common copynumber variations in the human genome. Am J Hum Genet. 2007; 80: 91-104.

18. Cahan P, Li Y, Izumi M, Graubert TA. The impact of copy number variation on local gene expression in mouse hematopoietic stem and progenitor cells. Nat Genet. 2009; 41: 430-7.

19. Perry GH, Yang F, Marques-Bonet T, Murphy C, Fitzgerald T, Lee AS, Hyland C, Stone AC, Hurles ME, Tyler-Smith C, Eichler EE, Carter NP, Lee C, et al. Copy number variation and evolution in humans and chimpanzees. Genome Res. 2008; 18: 1698-710.

20. Williams Rt, Lim JE, Harr B, Wing C, Walters R, Distler MG, Teschke M, Wu C, Wiltshire T, Su AI, Sokoloff G, Tarantino LM, Borevitz JO, et al. A common and unstable copy number variant is associated with differences in Glo1 expression and anxiety-like behavior. PLoS One. 2009; 4: e4649.

21. Santarius T, Bignell GR, Greenman CD, Widaa S, Chen L, Mahoney CL, Butler A, Edkins S, Waris S, Thornalley PJ, Futreal PA, Stratton MR. GLO1-A novel amplified gene in human cancer. Genes Chromosomes Cancer. 2010; 49: 711-25.
22. Öberg K, Castellano D. Current knowledge on diagnosis and staging of neuroendocrine tumors. Cancer and Metastasis Reviews. 2011; 30: 3-7.

23. Castellano D, Grande E, Valle J, Capdevila J, ReidyLagunes D, O'Connor JM, Raymond E. Expert consensus for the management of advanced or metastatic pancreatic neuroendocrine and carcinoid tumors. Cancer Chemother Pharmacol. 2015; 75: 1099-114.

24. Caplin ME, Pavel M, Cwikla JB, Phan AT, Raderer M, Sedlackova E, Cadiot G, Wolin EM, Capdevila J, Wall L, Rindi G, Langley A, Martinez S, et al. Lanreotide in metastatic enteropancreatic neuroendocrine tumors. N Engl J Med. 2014; 371: 224-33.

25. Rinke A, Muller HH, Schade-Brittinger C, Klose KJ, Barth P, Wied M, Mayer C, Aminossadati B, Pape UF, Blaker M, Harder J, Arnold C, Gress T, et al. Placebo-controlled, double-blind, prospective, randomized study on the effect of octreotide LAR in the control of tumor growth in patients with metastatic neuroendocrine midgut tumors: a report from the PROMID Study Group. J Clin Oncol. 2009; 27 : 4656-63.

26. Hosoda F, Arai Y, Okada N, Shimizu H, Miyamoto M, Kitagawa N, Katai H, Taniguchi H, Yanagihara K, Imoto I, Inazawa J, Ohki M, Shibata T. Integrated genomic and functional analyses reveal glyoxalase I as a novel metabolic oncogene in human gastric cancer. Oncogene. 2015; 34: 1196-206.

27. Rabbani N, Xue M, Thornalley PJ. Activity, regulation, copy number and function in the glyoxalase system. Biochem Soc Trans. 2014; 42: 419-24.

28. Xue M, Weickert MO, Qureshu SA, Kandala NN, Anwar A, Waldron M, Shafie A, Messenger D, Fowler M, Jenkins G, Rabbani N, Thornalley PJ. Improved glycemic control and vascular function in overweight and obese subjects by glyoxalase 1 inducer formulation Diabetes. 2016; 65: 2282-94.

29. Shafie A, Xue M, Thornalley PJ, Rabbani N. Copy number variation of glyoxalase I. Biochem Soc Trans. 2014; 42: 500-3.

30. O'Toole D, Couvelard A, Rebours V, Zappa M, Hentic O, Hammel P, Levy P, Bedossa P, Raymond E, Ruszniewski P. Molecular markers associated with response to chemotherapy in gastro-entero-pancreatic neuroendocrine tumors. Endocr Relat Cancer. 2010; 17: 847-56.

31. Davies L, Weickert MO. Gastroenteropancreatic neuroendocrine tumours: an overview. Br J Nurs. 2016; 25 : S12-5.

32. Krug S, Boch M, Daniel H, Nimphius W, Muller D, Michl P, Rinke A, Gress TM. Streptozocin-Based Chemotherapy in Patients with Advanced Neuroendocrine NeoplasmsPredictive and Prognostic Markers for Treatment Stratification. PLoS One. 2015; 10: e0143822.

33. Zatelli MC, Fanciulli G, Malandrino P, Ramundo V, Faggiano A, Colao A, Group N. Predictive factors of 
response to $\mathrm{mTOR}$ inhibitors in neuroendocrine tumours. Endocr Relat Cancer. 2016; 23: R173-83.

34. Allen RE, Lo TWC, Thornalley PJ. A simplified method for the purification of human red blood cell glyoxalase. I. Characteristics, immunoblotting, and inhibitor studies. Journal of Protein Chemistry. 1993; 12: 111-9.

35. Khan AM, Rajpoot N, Treanor D, Magee D. A Nonlinear Mapping Approach to Stain Normalization in Digital Histopathology Images Using Image-Specific Color Deconvolution. Ieee Transactions on Biomedical Engineering. 2014; 61: 1729-38.

36. Khan AM, Mohammed AF, Al-Hajri SA, Al Shamari HM, Qidwai U, Mujeeb I, Rajpoot NM, Ieee. (2014). A Novel System for Scoring of Hormone Receptors in Breast Cancer Histopathology Slides. 2014 Middle East Conference on Biomedical Engineering. (New York: Ieee), pp. 155-8.

37. Hansen MB, Nielsen SE, Berg K. Re-examination and further development of a precise and rapid dye method for measuring cell growth/cell kill. Journal of Immunological Methods. 1989; 119: 203-10.

38. Basu B, Sirohi B, Corrie P. Systemic therapy for neuroendocrine tumours of gastroenteropancreatic origin. Endocrine-Related Cancer. 2010; 17: R75-R90.

39. Klopfleisch R, Weiss ATA, Gruber AD. Excavation of a buried treasure - DNA, mRNA, miRNA and protein analysis in formalin fixed, paraffin embedded tissues. Histology and Histopathology. 2011; 26: 797-810.

40. Wang L-Y, Hung C-L, Chen Y-R, Yang JC, Wang J, Campbell M, Izumiya Y, Chen H-W, Wang W-C, Ann DK, Kung H-J. KDM4A coactivates E2F1 to regulate PDK-dependent metabolic switch between mitochondrial oxidation and glycolysis. Cell reports. 2016; 16: 3016-27.

41. Thornalley PJ, Rabbani N. Detection of oxidized and glycated proteins in clinical samples using mass spectrometry - A user's perspective. Biochimica et Biophysica Acta (BBA) - General Subjects. 2014; 1840: 818-29.

42. Pavel M, Baudin E, Couvelard A, Krenning E, Oberg K, Steinmuller T, Anlauf M, Wiedenmann B, Salazar R, Barcelona Consensus Conference p. ENETS Consensus Guidelines for the management of patients with liver and other distant metastases from neuroendocrine neoplasms of foregut, midgut, hindgut, and unknown primary. Neuroendocrinology. 2012; 95: 157-76.

43. Kim MJ, Kim DW, Lee BR, Shin MJ, Kim YN, Eom SA, Park BJ, Cho YS, Han KH, Park J, Hwang HS, Eum WS, Choi SY. Transduced Tat-glyoxalase protein attenuates streptozotocin-induced diabetes in a mouse model. Biochem Biophys Res Commun. 2013; 430: 294-300.

44. Lo TW, Thornalley PJ. Inhibition of proliferation of human leukaemia 60 cells by diethyl esters of glyoxalase inhibitors in vitro. Biochem Pharmacol. 1992; 44: 2357-63.
45. Thornalley PJ, Edwards LG, Kang Y, Wyatt C, Davies N, Ladan MJ, Double J. Antitumour activity of S-pbromobenzylglutathione cyclopentyl diester in vitro and in vivo. Biochemical Pharmacology. 1996; 51: 1365-72.

46. Falconi M, Eriksson B, Kaltsas G, Bartsch DK, Capdevila J, Caplin M, Kos-Kudla B, Kwekkeboom D, Rindi G, Kloppel G, Reed N, Kianmanesh R, Jensen RT, et al. ENETS Consensus Guidelines Update for the Management of Patients with Functional Pancreatic Neuroendocrine Tumors and Non-Functional Pancreatic Neuroendocrine Tumors. Neuroendocrinology. 2016; 103: 153-71.

47. Vinik A, Casellini C, Perry RR, Feliberti E, Vingan H. (2015). Diagnosis and Management of Pancreatic Neuroendocrine Tumors (PNETS). In: De Groot LJ, BeckPeccoz P, Chrousos G, Dungan K, Grossman A, Hershman JM, Koch C, McLachlan R, New M, Rebar R, Singer F, Vinik A and Weickert MO, eds. Endotext. (South Dartmouth (MA).

48. Vinik A, Feliberti E, Perry RR. (2014). Carcinoid Tumors. In: De Groot LJ, Beck-Peccoz P, Chrousos G, Dungan K, Grossman A, Hershman JM, Koch C, McLachlan R, New M, Rebar R, Singer F, Vinik A and Weickert MO, eds. Endotext. (South Dartmouth (MA).

49. Fraenkel M, Kim M, Faggiano A, de Herder WW, Valk GD, NETwork ObotK. Incidence of gastroenteropancreatic neuroendocrine tumours: a systematic review of the literature. Endocrine-Related Cancer. 2014; 21: R153-R63.

50. Hassan MM, Phan A, Li D, Dagohoy CG, Leary C, Yao JC. Risk factors associated with neuroendocrine tumors: A U.S.-based case-control study. International Journal of Cancer. 2008; 123: 867-73.

51. Giovannucci E, Harlan DM, Archer MC, Bergenstal RM, Gapstur SM, Habel LA, Pollak M, Regensteiner JG, Yee D. Diabetes and Cancer. A consensus report. 2010; 33: 1674-85.

52. Rabbani N, Xue M, Thornalley Paul J. Methylglyoxalinduced dicarbonyl stress in aging and disease: first steps towards glyoxalase 1-based treatments. Clinical Science. 2016; 130: 1677-96.

53. Calle EE, Kaaks R. Overweight, obesity and cancer: Epidemiological evidence and proposed mechanisms. Nature Reviews Cancer. 2004; 4: 579-91.

54. Perysinakis I, Aggeli C, Kaltsas G, Zografos GN. Neoadjuvant therapy for advanced pancreatic neuroendocrine tumors: an emerging treatment modality? Hormones (Athens). 2016; 15: 15-22.

55. Rabbani N, Xue M, Thornalley PJ. Dicarbonyls and glyoxalase in disease mechanisms and clinical therapeutics. Glycoconjugate Journal. 2016; 33: 513-25.

56. Rabbani N, Thornalley PJ. Methylglyoxal, glyoxalase 1 and the dicarbonyl proteome. Amino Acids. 2012; 42: 1133-42. 